\title{
Estimating risk of tobacco-induced mortality from readily available information
}

\author{
Richard Taylor
}

Abstract

Objectives - To estimate life expectancy and absolute risk of death before age 75 years in smokers and never-smokers in a population, and to estimate the number of excess deaths and person-years of life lost in 15-year-old smokers compared to never-smokers in such a population.

Design-An actuarial analysis using cross-sectional all-cause mortality and smoking data for the mid to late 1980s. Age-specific mortality rates in neversmokers were estimated using the agespecific population rates and the aetiological fraction for tobacco smoking determined by the indirect method. Relative risks for smokers versus neversmokers were used to calculate agespecific rates in various categories of smoker.

Setting - New South Wales (NSW), Australia. Mid 1980s to 1990 .

Subjects - State population: 5.8 million in 1990: 15 -year-old male smokers: 8816 in 1990.

Main outcome measures-The parameters calculated for smokers and neversmokers were: life expectancy (at age 15 years); actuarial cumulative risk for allcause mortality for the age range 15-74 years; and excess deaths and personyears of life lost by age 74 years due to tobacco smoking in yearly cohorts of 15year-old boys in NSW.

Results - In males, conditional life expectancy for 15-year-olds was 77.2 years in never-smokers, 73.1 years in eversmokers, and 71.6 years in heavy smokers (defined as smokers of more than one packet per day). The risk of premature death (before age 75 years) in 15-year-old boys was $35 \%$ in never-smokers ( 1 in 3 ), $50 \%$ in ever-smokers ( 1 in 2$)$, and $56 \%$ in heavy smokers $(1$ in 1.8$)$.

$A$ one-year cohort of 15-year-old male smokers (8816) can be expected to produce 1292 to 1841 excess deaths and 23485 to 33895 extra person-years of life lost to age 74 years, for ever-smokers and heavy smokers, respectively. Using data on brand preference, 569 to 810 of these excess deaths will occur in 15-year-olds who presently smoke Winfield cigarettes (for ever-smokers and heavy smokers, respectively), with lesser numbers apportioned to Peter Jackson, Benson and Hedges, and Longbeach.

Conclusions-Plausible estimates can be made for absolute risk from tobacco smoking using cross-sectional data on mortality and smoking prevalence. Number of future excess deaths and person-years of life lost in current smokers can also be estimated. Projections describe what will happen if the current situation does not change.

(Tobacco Control 1993; 2: 18-23

\section{Introduction}

Tobacco smoking has long been regarded as an important causative factor in a wide range of diseases which contribute to premature mortality, particularly lung cancer and coronary heart disease. Tobacco smoking also leads to greater morbidity (illness) in smokers compared with non-smokers as a consequence of the medical conditions to which it contributes.

Important statistical information on the relation of tobacco smoking to particular diseases and all-cause mortality has been produced by cohort studies of British doctors, ${ }^{1-4}$ US Veterans, ${ }^{5,6}$ and the American Cancer Society Volunteer study. ${ }^{7}$ These studies were reviewed in detail in the US Surgeon General's 1982 report on smoking and health, ${ }^{8}$ and in an extensive review on avoidable cancer, including tobacco-induced, performed by Doll and Peto. ${ }^{9}$ Another longitudinal study (Cancer Prevention Study II (CPS-II)) in the US is continuing at present. ${ }^{10}$

Calculations of tobacco-attributable deaths from all causes and particular causes, potential years of life lost (PYLL), number of incident cancers, and hospital utilisation can be estimated by application of the aetiological fraction (AF). For example, calculations have been made for Australia and Western Australia by Holman et al. ${ }^{11,12}$ The AF in these studies was calculated by the indirect method using relative risks from an international meta-analysis and local information on prevalence of smoking.

There is also another way of displaying the information on the disease burden from smoking which helps to bring home the risk to the individual smoker, by calculating the absolute risks of death in various types of smokers, and in never-smokers. Accumulation of risk over several decades is a more informative way of presenting this information.

Information from cohort studies of tobacco smoking can provide data which enable calculation of an individual absolute risk of mortality or illness attributable to smoking. Most cohort studies available ${ }^{8}$ were conducted over long periods of time (during which 
mortality from all causes and various causes changed) and were completed more than two decades ago. Furthermore, these cohorts have not been random samples of the population, and the most recent study (CPS-II) is also affected by the "healthy volunteer" effect. ${ }^{13}$ While the relative risks of mortality or illness between never-smokers and various kinds of smokers are likely to be valid in similar populations the absolute risks cannot be translated in the same way.

Mattson et al. ${ }^{14}$ ovecame some of the above problems by "forcing" the weighted average of mortality rates from particular smokingrelated diseases, for various categories of smokers, derived from the US veterans cohort study conducted during the 1950s and 1960 s, onto the 1982 US mortality rates from these diseases. The weights for proportions of various kinds of smokers were derived from a national US health interview survey in 1983. There were problems with this methodology, particularly in relation to lung cancer, and various adjustments were made.

The overall approach to calculating risks for populations employed by Mattson et al. ${ }^{14}$ and others is similar to the concept behind the cross-sectional life table. That is, current agespecific death rates (or incidence rates) are used to construct synthesised cohort probabilities of dying or developing disease which would apply to an individual if he or she moved successively through the age ranges included in the calculations. Thus, parameters generated from the analysis apply to the future if current age-specific death and incidence rates continue.

While there are several publications concerning the risk of incidence and mortality for various cancers (including tobacco-related cancers) for whole populations, ${ }^{15-19}$ there have been very few publications which have tried to estimate the risk of mortality in smokers and never-smokers.

The method proposed in this report for estimating all-cause mortality and lung cancer incidence and mortality in smokers and neversmokers using the aetiological fraction is similar to that suggested by Cornfield, ${ }^{20}$ and extended by Cutler and Loveland, ${ }^{21}$ who used relative risks, population incidence, and proportions of cases and controls exposed to the risk factor. Day ${ }^{22}$ has also proposed a similar procedure for calculation of the cumulative risk in smokers using the cumulative risk in the population, the relative risk, and population prevalence of smoking. However, the formulations of Cornfield, ${ }^{20}$ Cutler and Loveland, ${ }^{21}$ and that of Day, ${ }^{22}$ are not widely known or used, and neither approach explicitly employs age-specific applications of relative risks and smoking prevalence.

This paper employs calculations to estimate absolute risks of premature death for male smokers and never-smokers of New South Wales (NSW), Australia, and uses these data to estimate future deaths in 15-year-old smokers and non-smokers. The purpose of the analysis is to generate data which can be more readily assimilated by the general public.

\section{Methods}

The empirical data on all-cause mortality for NSW in 1987 were obtained from the NSW Registrar of Births, Deaths and Marriages, via the Australian Bureau of Statistics. Tabulations by gender and 5-year age groups were made from unit record data tapes. Population denominators from censuses were obtained from the Australian Bureau of Statistics. Yearly estimated resident populations stratified by gender and 5-year age group were obtained.

Aetiological fractions (AF) for the Australian population for tobacco-related mortality (all-causes) were obtained from Holman et al. ${ }^{11}$ The AFs used were for ever-smokers, and were available by gender and age group for all-cause mortality. The data on smoking prevalence in the Australian population used in these $\mathrm{AF}$ calculations were from $\mathrm{Hill}^{23}$ and apply to the year 1986 . The relative risks for tobacco smoking used in these AF calculations for total mortality were derived from the large British and US cohort studies previously mentioned. Pooled relative risks were calculated from these data.

The same relative risks can be used for females as for males. As Holman et al. ${ }^{11}$ point out, the data for women are scant and were collected during a period in which cigarette consumption and inhalation were far lower in women than in men - a situation which may no longer exist.

The AF was calculated by Holman et al. ${ }^{11}$ derived from the relative risk (RR) and the proportion of the population exposed to the risk factor (p) using the indirect method. ${ }^{11,24}$

$\mathrm{AF}=\frac{\mathrm{p}(\mathrm{RR}-1)}{\mathrm{p}(\mathrm{RR}-1)+1}$

The algebraic expression for calculating AF using the direct method is : ${ }^{24}$

$A F=\frac{I_{\text {due to exposure }}}{I_{p}}=\frac{I_{p}-I_{\text {ne }}}{I_{p}}$

where $I_{p}$ is the incidence (or mortality) rate in the whole population and $I_{n e}$ is the incidence (or mortality) rate in the non-exposed group.

Thus, $\mathrm{I}_{\mathrm{ne}}=\mathrm{I}_{\mathrm{p}}$ * $(1-\mathrm{AF})$

In other words, the age-specific mortality or incidence rates for never-smokers can be estimated by applying (1-AF) to the overall population mortality or incidence rates.

Once age-specific rates for mortality and incidence for never-smokers have been calculated, relative risks derived from various epidemiological studies can be applied to obtain age-specific mortality or incidence rates for various categories of smokers. The relative risks for never-smokers versus various categories of smoker were obtained from the metaanalysis by Holman et al. ${ }^{11}$ These data are similar to summaries contained in the 1982 US Surgeon General's report. ${ }^{8}$ As previously mentioned, the relative risks for males can be applied to the female data.

In this analysis, the categories used are never-smoker, ever-smoker, and heavy- 
Table 1 Estimates of life expectancies (yrs) and cumulative risk for mortality by smoking status for males in NSW, Australia

\begin{tabular}{|c|c|c|c|c|c|c|}
\hline & All & $\begin{array}{l}\text { Never-smokers } \\
(a)\end{array}$ & $\begin{array}{l}\text { Ever-smokers } \\
(b)\end{array}$ & $\begin{array}{l}\text { Difference } \\
(b)-(a)\end{array}$ & $\begin{array}{l}\text { Heavy smokers } \\
(c)\end{array}$ & $\begin{array}{l}\text { Difference } \\
(c)-(a)\end{array}$ \\
\hline \multicolumn{7}{|l|}{ Life expectancies (yrs) } \\
\hline Life expectancy at birth & 72.9 & 76.2 & 72.1 & 4.1 & 70.6 & 5.6 \\
\hline $\begin{array}{l}\text { Conditional life expectancy at age } \\
15 \mathrm{yrs}^{\star}\end{array}$ & 73.9 & 77.2 & 73.1 & 4.1 & 71.6 & 5.6 \\
\hline \multicolumn{7}{|l|}{$\begin{array}{l}\text { Cumulative (all-cause) mortality risk }{ }^{\star \star} \\
\text { Age } 15-74 \text { yrs }\end{array}$} \\
\hline $\begin{array}{l}\text { Cumulative mortality }(\%) \\
\text { Cumulative risk }(1 \text { in } x)\end{array}$ & & $\begin{array}{r}34.9 \\
2.9\end{array}$ & $\begin{array}{r}49.5 \\
2.0\end{array}$ & 14.6 & $\begin{array}{r}55.7 \\
1.8\end{array}$ & 20.8 \\
\hline
\end{tabular}

$\star$ The conditional life expectancy at age $15 \mathrm{yrs}$ is the life expectancy at age $15 \mathrm{yrs}$ plus $15 \mathrm{yrs}$

$\star \star$ Cumulative mortality risk is adjusted for population decline due to all-cause mortality.

Table 2 Future excess mortality by age 74 years in 8816 NSW 15-year-old boys who smoked in 1990

\begin{tabular}{lll}
\hline $\begin{array}{l}\text { Future expected premature } \\
\text { deaths }\end{array}$ & $\begin{array}{l}\text { Premature } \\
\text { deaths }\end{array}$ & $\begin{array}{l}\text { Excess premature } \\
\text { deaths in smokers }\end{array}$ \\
\hline If they are never-smokers & 3073 & - \\
If they are ever-smokers & 4365 & 1292 \\
If they are heavy smokers $(>1$ pkt/day) & 4914 & 1841 \\
\hline
\end{tabular}

For a decade of 15-year-old cohorts these figures can be multiplied by 10 .

smoker (more than one packet a day). A packet of cigarettes consisted of 20 individual cigarettes during the period the studies were carried out.

Age-specific mortality or incidence rates can be converted to cohort probabilities and summarised to assist with understanding of the data. The main summary measures used in this analysis are life expectancy and cumulative risk for all-cause mortality. Cross-sectional life tables were calculated from age-specific death rates using standard methods. ${ }^{25}$ The cumulative risk was calculated from the cumulative rate adjusted for population decline. ${ }^{22}$ The life tables can also be used to calculate cumulative risks between various ages using the survivorship function $\left(1_{x}\right)$. In these calculations the two methods produced almost identical estimates, and only one figure will be reported.

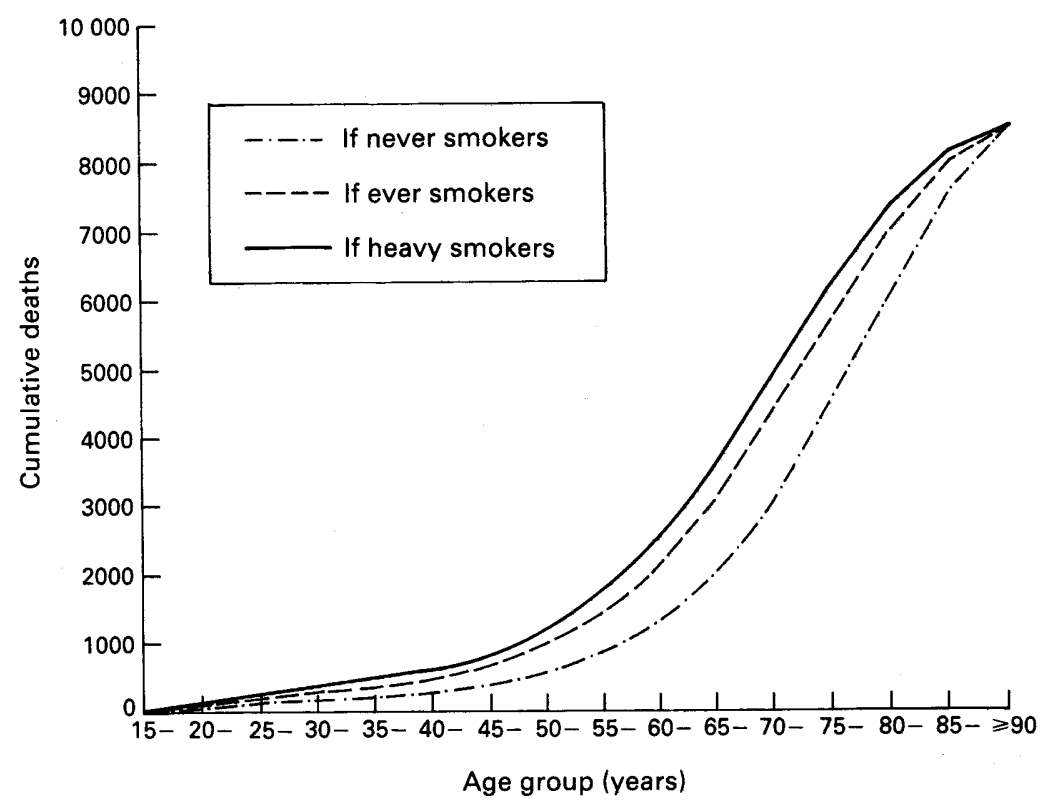

Figure 1 Projected cumulative deaths in NSW male smokers aged 15 years in 1990 using cross-sectional mortality data
The cumulative risk for mortality, and the life-table parameters, can be applied to populations in order to estimate number of cases of premature mortality expected in the future, if present mortality rates continue. Premature mortality for males was defined as $\leqslant 74$ years since this was the approximate average life expectancy at age 15 years in Australia in the late 1980s. The mid-decade age break was also chosen for ease of calculation.

Numbers of boys aged 15 years who smoked in 1990, from NSW survey data, have been projected on the NSW population to obtain estimated numbers of smokers aged 15 years in NSW. ${ }^{26}$ There were estimated to be 8816 male smokers aged 15 years in NSW in 1990.

The absolute number of deaths (age 1574 years) in this cohort projected into the future was estimated from the cumulative risk of mortality for never-smokers, ever-smokers, and heavy smokers. Cumulative mortality calculations produced the same result as summing the (life table) deaths in the intervals $\left(d_{x}\right)$ for 15-74 years after setting $l_{15}$ at the number of 15-year-old smokers.

The projected number of excess deaths in 15-year-olds due to smoking was calculated by deducting the deaths in smokers from the deaths had they been non-smokers for the age range $15-74$ years.

Numbers of future deaths due to smoking from successive cohorts of 15-year-old NSW boys were apportioned to various cigarette brands in proportion to brand preference obtained from survey data of 15-year-old smokers. ${ }^{26}$

The person-years of life lost due to smoking was obtained by deducting the person-years lived $\left(L_{x}\right)$ in the life table of never-smokers from the person-years lived in the life table of smokers, using 8816 males aged 15 years for the $l_{15}$.

\section{Results}

For NSW male never-smokers cumulative mortality (risk) (for the age range $15-74$ years) was $35 \%$ (1 in 3$)$. This increased to $50 \%$ (1 in 2) for ever-smokers, and $56 \%$ (1 in 1.8) for heavy smokers (table 1). Compared to neversmokers there is an increase of 15 percentage points in premature mortality (15-74 years) in ever-smokers, and an increase of 21 percentage points in heavy smokers.

Life expectancy at birth for NSW males was 


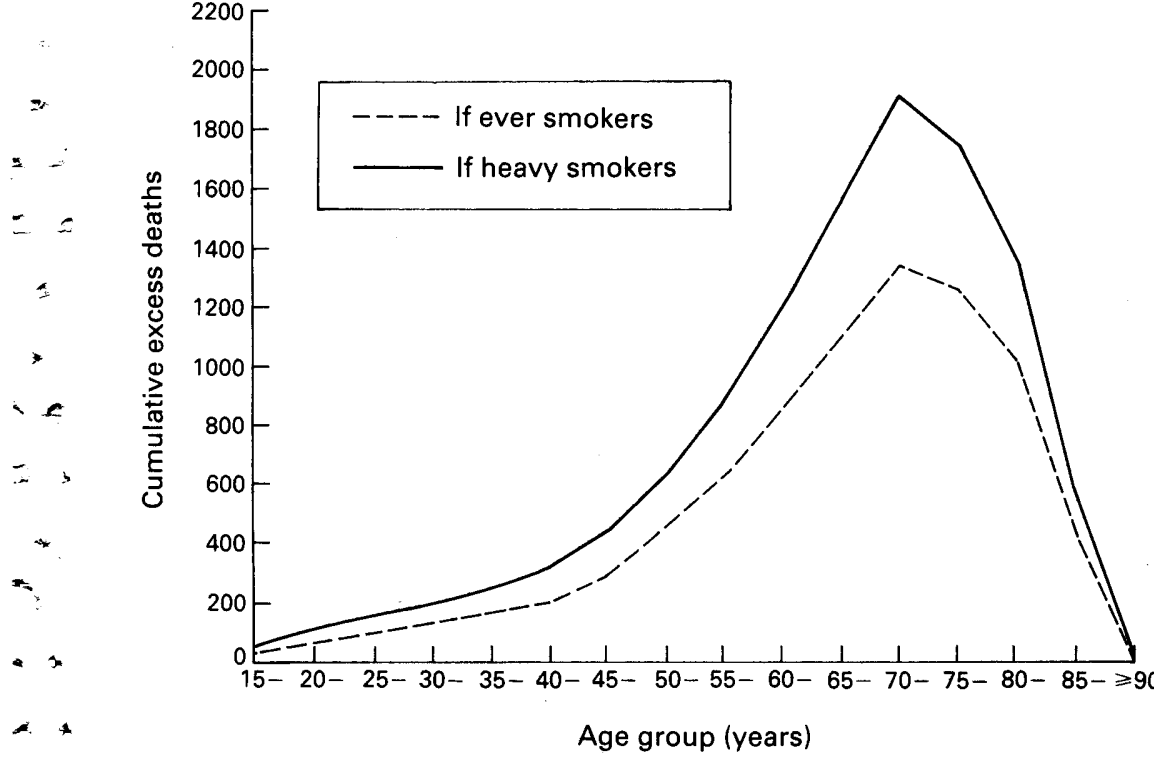

- Figure 2 Projected cumulative excess deaths in NSW male smokers aged 15 years in 1990 using cross-sectional mortality data
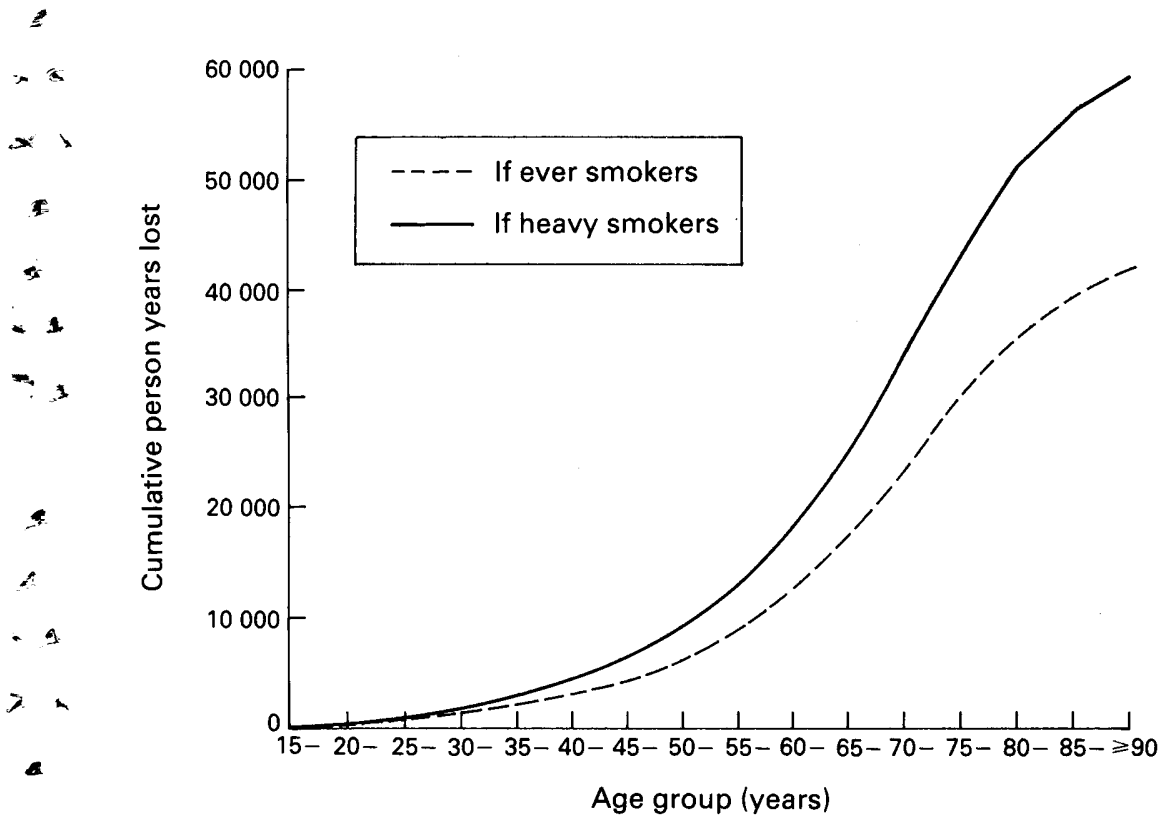

$=$

$\pm 3$

$=e$

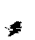

Table 3 Excess premature future deaths by age 74 years from a decade of successive cohorts of 15-year-old NSW boys who smoke, by major brand of cigarette smoked at age 15 years.

$-$

$-2$

$-6$

.7 smokers
If they are heavy
If they are everIf they are
smokers smokers

\begin{tabular}{|c|c|c|c|c|c|}
\hline & \multirow{2}{*}{$\begin{array}{l}\text { Total } \\
\text { excess } \\
\text { premature } \\
\text { deaths in } \\
\text { smokers } \\
\text { from } 10 \\
\text { cohorts } \\
(n=88160)\end{array}$} & \multicolumn{4}{|c|}{ Excess premature deaths $(\%)$} \\
\hline & & $\begin{array}{l}\text { Winfield } \\
\text { smokers } \\
(44 \%)\end{array}$ & $\begin{array}{l}\text { Peter } \\
\text { Jackson } \\
\text { smokers } \\
(15 \%)\end{array}$ & $\begin{array}{l}\text { Benson } \mathcal{G} \\
\text { Hedges } \\
\text { smokers } \\
(8 \%)\end{array}$ & $\begin{array}{l}\text { Longbeach } \\
\text { smokers } \\
(11 \%)\end{array}$ \\
\hline $\begin{array}{l}\text { If they are ever- } \\
\text { smokers }\end{array}$ & 12920 & 5685 & 1938 & 1034 & 1421 \\
\hline $\begin{array}{l}\text { If they are heavy } \\
\text { smokers }\end{array}$ & 18410 & 8100 & 2762 & 1473 & 2024 \\
\hline
\end{tabular}

72.9 years and conditional life expectancy at age 15 years was 73.9 years (table 1). For never-smokers, life expectancy at birth was estimated at 76.2 years and conditional life expectancy at age 15 years was 77.2 years. For ever-smokers life expectancy at birth decreased to 72.1 years and conditional life expectancy at age 15 years was reduced to 73.1 years; for heavy smokers life expectancy at birth decreased to 70.6 years and conditional life expectancy at age 15 years was 71.6 years.

Using actuarial cumulative mortality for 15-74 years in NSW males it is estimated that the 8816 boys who constitute the 1990 cohort of boys aged 15 years who smoke will generate 1292 excess deaths by age 74 years if classified as ever-smokers, or 1841 excess deaths if classified as heavy smokers (compared to never-smokers) (see table 2).

The expected deaths and excess deaths in smokers, by age interval of death from 1 year of 15-year-old NSW school children who smoke, are plotted in figures 1 and 2 . Almost $40 \%$ of excess deaths (before age 75 years) occur before age 60 years for ever-smokers or heavy smokers.

By deduction of person-years lived in cohorts of smokers from the cohort of neversmokers, the excess person-years lost due to smoking can be estimated (figure 3). The person-years lost (between ages 15-74 years) from 8816 boys aged 15 years would be 23485 if ever-smokers, and 33895 if heavy smokers. The excess person-years of life lost in an entire lifetime would be 41867 for an ever-smoker cohort and 58936 for a heavy smoker cohort (compared to never-smokers).

Using 1990 survey data on brand preference $^{26}$ it is possible to apportion future excess premature deaths among 15-year-old smokers to the various cigarette brands they smoked at age 15 years (table 3). From a decade of cohorts of 15-year-old boys in NSW : 5690 to 8100 excess deaths will occur in Winfield smokers; 1938 to 2762 excess deaths in Peter Jackson smokers; 1034 to 1473 excess premature deaths in Benson and Hedges smokers; and 1421 to 2024 excess deaths in LongBeach smokers.

\section{Discussion}

The estimation of future risks for mortality and disease incidence in smokers and neversmokers poses problems even in countries where cohort studies of the health consequences of smoking have been performed. This is because most of these cohort studies were performed more than 20 years ago, and absolute risks cannot be directly applied to the present in which mortality rates in adults are considerably lower, due in large part to lower coronary heart disease mortality - which is partly smoking-related. Furthermore, previous and present cohorts used for these studies have not been representative of the general population, and absolute mortality findings are not directly generalisable. Finally, the use of relative risks for mortality and disease incidence in smokers and neversmokers derived from the older cohort studies (as in this analysis) will yield conservative estimates of the impact of smoking because more recent cohort studies (eg, CPS-II) show higher relative risks, even among men. ${ }^{27}$ However, relative risks for mortality and disease 
incidence in smokers and non-smokers are likely to be valid and applicable to similar populations.

Current smoking data were used in the AF calculations presented here. There are some difficulties in employing this approach when attributing current deaths to smoking because current mortality is a function of the previous smoking behaviour of successive cohorts. However, this use of current smoking prevalence may be less of a problem for estimating future deaths.

The estimates produced in this paper are based on contemporary mortality data. The use of life-table methods and cumulative risks derived from cross-sectional data are useful for quantification of what would happen to an individual or group if they passed through the age-specific rates used in the calculations.

The application of life expectancies and cumulative risks to the future is made with the caveat that this is what would be expected to happen if contemporary age-specific rates within smoking categories continued.

The results have been mostly presented as individual or group risks (and life expectancies) by smoking status for 15-year-olds since there is current debate in many countries concerning the acquisition of the smoking habit and its health effects in this age group. Cumulative risks by smoking status have been calculated from age 15 years to the male life expectancy for the total population. This method was chosen to emphasise the mortality burden prior to this age and to pre-empt criticism that excess mortality in smokers is predominantly a problem of old age (everybody has to die of something).

The choice of 74 years for males as defining the upper limit of premature death is conservative, since it corresponds to the approximate conditional life expectancy at age 15 years for the whole population, including smokers. It may also have been defensible to have chosen conditional life expectancies at age 15 years in never-smokers to define premature death. In this case, premature death would be greater than or equal to 77 years in males. Calculations using these figures would have produced estimates showing a higher burden of premature mortality due to smoking. (For ease of calculations, mid- or end-decade ages should be chosen since the available data are usually supplied in five-year age brackets.)

The results obtained in this study can be compared to the findings of actual cohort studies of the relation of tobacco smoking to all-cause and cause-specific mortality. The purpose of these comparisons is to determine the plausibility of the estimates. Comparisons are made between the ratio of deaths in male smokers versus never-smokers, and ratios of mortality rates or probabilities of dying in male smokers versus never-smokers. Using the NSW estimates from this report, the ratio of deaths in smokers to deaths in never-smokers was 1.5. The average premature deaths in eversmokers and heavy smokers was used to derive this figure. Actuarial cumulative mortality from NSW calculations (males 15-74 years) was 0.50 for ever-smokers and 0.35 for neversmokers, which is a ratio of 1.43 .

Hammond and Horn ${ }^{7}$ followed 187783 white US males aged 50-69 years for approximately 3 years (mid-1952 to mid-1955). There were 11870 deaths. The ratio of deaths in smokers (7316) compared to expected numbers had they been never-smokers (4651) was 1.57 . As a result of 20 years observation on male British medical doctors, Doll and Peto ${ }^{3}$ produced data which indicated a ratio of all-cause mortality of 1.33 based on age-standardised (all ages) death rates for smokers versus neversmokers. Probabilities of death over 16 years 1954-1969 were calculated for 293958 US veterans with life insurance aged 55-64 at inception of follow-up by Rogot. ${ }^{5}$ These probabilities were 0.46 for cigarette smokers, and 0.29 for never-smokers, which is a ratio of 1.59. It can be concluded that estimates produced in this report do not vary greatly from statistics from published cohort studies, considering the different populations employed.

The study by Mattson et al. ${ }^{14}$ on risk of death from tobacco smoking in the US population in 1982 used cross-sectional data, although the methods employed were different in other respects from this report. Mattson et al..$^{14}$ reported probabilities of dying due to all smoking-related diseases for 35-year-old men before the age of 75 years as $11 \%$ for former smokers, $17 \%$ for current smokers of less than 25 cigarettes per day, and $28 \%$ for current smokers of 25 or more cigarettes per day. The excess cumulative mortality using the NSW definitions and calculations for males at age 35 years, of dying before age 75 years, was $15 \%$ for ever-smokers and $21 \%$ for heavy smokers. Taking into consideration the different categorisation of tobacco smoking and declining coronary heart disease mortality during the 1980s, the NSW data are consistent with the study by Mattson. ${ }^{14}$

The recent study by Peto et al., ${ }^{13}$ which estimated tobacco-attributable mortality (3569 years) for developed countries using the excess lung cancer mortality rate (compared to a large cohort study of never-smokers) as an indicator, produced estimates for Australia (around 1990) of $9 \%$ for males. Using tobaccoattributable mortality for ages 35-69 years in ever-smokers from this study, and the proportion of these persons in the Australian population around 1990 (males: $66 \%$, females $44 \%$ ), it was estimated that comparable data for tobacco-attributable mortality in the NSW population would be $7.3 \%$ for males.

Using survey data on smoking in school children by single years of age it is possible to estimate total numbers of smokers at age 15 years by gender in NSW. Using survival analysis from the cross-sectional life tables, or the actuarial cumulative rate, it is possible to determine the projected deaths of 15-year-old smokers or never-smokers. The caveat is that present cross-sectional mortality of smokers and never-smokers continues into the future. These projected deaths can be specified within age groups and aggregated from age 15 years to 
the conditional life expectancy at age 15 years. By subtracting the deaths in never-smokers from the deaths in smokers, the excess deaths due to tobacco can be estimated. Cumulative excess deaths by age can be calculated since it is important to demonstrate that excess deaths occur from age 35 onwards, and are not entirely clustered in the over-70s. In the NSW calculations, around $40 \%$ of excess deaths before age 75 years occurred before age 60 years.

This point is also borne out by comparison of cumulative excess person-years of life lost by age in smokers compared to never-smokers. The excess person-years of life lost in various categories of smokers can be estimated by subtraction from person-years of life lost in never-smokers.

If survey data are available on brand preference amongst 15-year-olds, this information can be used to apportion deaths to the various brands smoked at age 15 years. Brands smoked by 15 -year-olds are important because they are closely associated with smoking initiation. Brand switching may occur, although this is not the aim of tobacco companies that attempt to maintain and increase market share. Excess deaths due to tobacco in market economies are a consequence of smoking advertised brands of cigarettes; generic products are unavailable or have a small market share.

In this paper only male rates are estimated for the sake of brevity. Similar calculations can be performed for females, although male relative risks are usually employed. This analysis has focussed on all-cause mortality. Similar calculations can be performed using cause-specific mortality and incidence of smoking-related diseases. Estimates of cumulative risk for particular disease incidence or mortality in smokers and never-smokers can be adjusted for competing risks of death from other causes.

The analysis described in this paper produces statistics which are useful for health promotion because they are meaningful for ordinary people. Death rates in smokers and never-smokers can be estimated from local data on smoking prevalence and age-specific mortality, and information on relative risk. Data expressed as cumulative absolute risk, life expectancy, or numbers of deaths are more intuitively understandable than relative risk or rates of incidence or mortality.

1 Doll R, Hill AB. Mortality in relation to smoking: ten years' observations of British doctors. BMF 1964; 1: 1399-410. 2 Doll R, Pike MC. Trends in mortality among British doctors in relation to their smoking habits. $\mathcal{f} R$ Coll Physicians Lond 1972; 6: 216-22.
3 Doll R, Peto R. Mortality in relation to smoking: 20 years' observations on male British doctors. BMF 1976;2: 1525-36.

4 Doll R, Gray R, Hafner B, Peto R. Mortality in relation to smoking: 22 years' observations on female British doctors. BMF 1980; 967-71.

5 Rogot E. Smoking and mortality among US veterans. $f$ Chron Dis 1974; 27: 189-203.

6 Rogot E, Murray JL. Smoking and causes of death among US veterans: 16 years of observation. Public Health Reports, May-June 1980; 95: 213-22.

7 Hammond EC, Horn D. Smoking and death rates-report on forty-four months of follow-up of 187,783 men. II death forty-four months of follow-up of 187,783 men. II death
rates by cause. $7 \mathrm{Am} \mathrm{Med} \mathrm{Assoc} \mathrm{1958;166:1294-1308.}$

8 US Department of Health and Human Services. The health consequences of smoking: cancer. A report of the Surgeon General, 1982. Rockville, Maryland: Public Health Service, Office on Smoking and Health, 1982. (DHHS Publication No. (PHS) 82-50179.)

9 Doll R, Peto R. The causes of cancer: quantitative estimates of avoidable risk of cancer in the United States today. $\mathcal{F}$ Natl Cancer Inst 1981; 66: 1192-1308.

10 Garfinkel L. Selection, follow-up and analysis in the American Cancer Society prospective studies. In: Garfinkel L., Ochs O., Mushinski M. Eds. NCI monograph 67. National Cancer Institute NIH publication No. $85-2713,1985$; 49-52.

11 Holman C, Armstrong B, Arias L, Martin C, Hatton W, Hayward L, Salmon $M$, Shean $R$, Waddell V. The quantification of drug caused morbidity and mortality in quantification of drug caused morbidity and mortality in
Australia 1988. Department Community Services and Australia 1988.

12 Holman C, Shean R. Premature adult mortality and shortstay hospitalisation in Western Australia attributable to the smoking of tobacco 1979-83. Med $\mathcal{F}$ Aust 1986; 145 $7-11$.

13 Peto R., Lopez A., Boreham J., Thun M., Heath C. Mortality from tobacco in developed countries: indirect estimation from national vital statistics. Lancet 1992 339: 1268-78.

14 Mattson ME, Pollack ES, Cullen JW. What are the odds that smoking will kill you? Am Y Public Health 1987; 77 : 425-31.

15 Seidman H, Silverberg E, Bodden A. Probabilities of eventually developing and of dying of cancer (risk among persons previously undiagnosed with the cancer). $\mathrm{Ca}-\mathrm{A}$ persons previously undiagnosed with the can
Cancer J for Clinicians $1978 ; 28: 33-46$.

16 Seidman H, Mushinski MH, Gelb SK, Silverberg E. Probabilities of eventually developing or dying of cancer - United States. Ca-A Cancer J for Clinicians 1985 ; 35 : 36-56.

$17 \mathrm{Zdeb}$ MS. The probability of developing cancer. $A m \mathcal{f}$ Epidemiol 1977; 106: 6-16.

18 Cutler S, Haenszel W. The magnitude of the cancer problem. Public Health Reports 1954; 69: 333-9.

19 Goldberg ID, Levin ML, Gerhardt PR, Handy VH, Cashman RE. The probability of developing cancer. $\mathcal{f}$ Natl Cancer Inst 1956; 17: 155-73.

20 Cornfield J. The estimation of the probability of developing a disease in the presence of competing risks. Am $\mathcal{F}$ Public 47: $601-7$

21 Cutler SJ, Loveland DB. The risk of developing lung cancer and its relationship to smoking. $f$ Natl Cancer Inst 1954; 15: 201-11.

22 Day N. Cumulative rate and cumulative risk. Chapter 10. In: Cancer Incidence in Five Continents, Volume V. Eds: Muir C, Waterhouse J, Mack T, Powell J, Whelan S. IARC Scientific publication 1987, No. 88. International Agency for Research on Cancer, Lyon.

23 Hill DJ. Australian patterns of tobacco smoking in 1986 Med $\mathcal{f}$ A Ast 1988; 149: 6-10.

24 Armitage P, Berry G. Statistical methods in medical research. Blackwell Scientific Publications 1987, Second Edn.

25 Pollard AH, Yusuf F, Pollard GN. Demographic Techniques. Pergamon Press, 1974

26 Edwards K, White VM, Hill DJ. Cigarette and alcohol consumption among New South Wales secondary school consumption among New South Wales secondary school children in 1990. Cancer Council NSW and Centre for Behavioural Rese

27 US Department of Health and Human Service. Reducing the health consequences of smoking : 25 years of progress. A report of the Surgeon General, 1989. Atlanta, Georgia : Centers for Disease Control, Office on Smoking and Health, 1989: chapter 3. (DHHS Publication No. (CDC) 89-8411.) 